\title{
Performance of new multi chamber systems vs. conventional Jarlan caisson breakwaters
} Hendrik Bergmann ${ }^{*}$, Hocine Oumeraci ${ }^{* *}$

* Research Assistant, Leichtweiss-Institute, Technical University of Braunschweig, Beethovenstr. 51a, 38106 Braunschweig, Germany

**Full Professor, Leichtweiss-Institute and Joint Coastal Engineering Research Centre (FZK) of the Universities of Hannover and Braunschweig

\section{Résumé}

L'efficacité hydraulique d'écrans simples et des systèmes à chambre(s) a été étudiée du point de vue fonctionement et réduction d'efforts lors d'un programe experimental détaillé dans le Grand Canal à Houle (GWK) de Hanovre. Une comparaison des systèmes monochambre et multichambres en termes de pouvoir réfléchisant et d'efforts de la houle illustre clairement les avantages des systèmes multichambres. Les différences de phase entre la paroi amont et la paroi arrière sont aussi examinées et discutées.

\begin{abstract}
The hydraulic performance and wave loads of single screens and chamber systems were investigated within an extensive test programme in the Large Wave Flume (GWK), Hannover, of the "Forschungszentrum Küste (FZK)", a joint coastal engineering research centre of both Universities Hannover and Braunschweig. A comparison of One- and Multi-Chamber-Systems in terms of the reflection properties and the wave loads demonstrates the advantages of systems with more than one wave chamber. The analysed phase lag between front wall and rear wall of One Chamber Systems is investigated and discussed in this paper.
\end{abstract}

\section{Introduction}

Breakwaters and seawalls have to cope with muitiple demands and boundary conditions. In many cases these structures are built in larger water depths as jetties for oil refineries, structures for tsunami protection, etc.. In such cases the design of caisson breakwaters may be advantageous, as they require less space, less material and less time for construction. But due to the vertical impermeable front, strong reflections of the incoming waves occur at the structure, which may cause manifold problems (ship navigation, wave overtopping, local scour, etc.).

To reduce these drawbacks additional improvements in the design were necessary. In 1960 Jarlan introduced the principle of energy dissipating chambers with perforated front walls (perforated caissons). The incident wave energy is partly reflected at the perforated seaward wall and is partly transmitted through the openings into the wave chamber where a certain amount of the energy is dissipated due to resonance 
phenomena, vortices and friction losses governed mainly by the porosity of the perforated wall and by the $B / L$ ratio (chamber width/wave length). Besides the original design with a single wave chamber several innovative alternatives have been investigated to further improve the hydraulic performance and to enhance the structure stability. But even with consideration of these manifold studies on various innovative structure types, several key aspects associated with the hydraulic processes remain unclear. Therefore an extensive large scale test programme was implemented within a joint research project of the Institute of Naval Architecture (Berlin) and the Leichtweiss-Institute (Braunschweig) to investigate the hydraulic behaviour and the wave loads of single perforated walls, One Chamber Systems (OCS) and Multi Chamber Systems (MCS).

\section{Experimental set-up and test conditions}

The model tests on single filter walls, one chamber systems (OCS) and multi chamber systems (MCS) were conducted at the Large Wave Flume (GWK) in Hannover, Germany. The flume has a length of $320 \mathrm{~m}$, a width of $5 \mathrm{~m}$ and a depth of $7 \mathrm{~m}$. Before investigating the chamber systems, systematic tests on single wave screens with different porosities have been performed. The vertical permeable walls, constructed of horizontal steel bars $(180 \times 180 \mathrm{~mm})$ were used for both the single walls and the chamber systems. The structure porosity $\varepsilon=s / e$, with gap spacing $\mathrm{s}$ and distance $\mathrm{e}$ between two element axis, varied between $\varepsilon=0 \%, 11 \%, 20 \%, 26.5 \%$ and $40.5 \%$. The vertical perforated walls have a structure height of $6 \mathrm{~m}$, so that wave overtopping is negligible. OCS and MCS were installed at a distance of roughly $145 \mathrm{~m}$ from the wave maker. Up to 125 measuring devices (wave gauges, current meters, pressure transducers, force meters, etc.) were installed to measure the wave conditions in front and inside the structure and the wave loads acting on the walls. As an example, Fig. 1 shows the longitudinal section of OCS2 with locations of the measuring devices. The incident waves and wave reflection were analysed by groups of wave gauges (with 4 wave gauges each) in front of the structure using the Mansard-Funkemethod (Mansard and Funke, 1987).

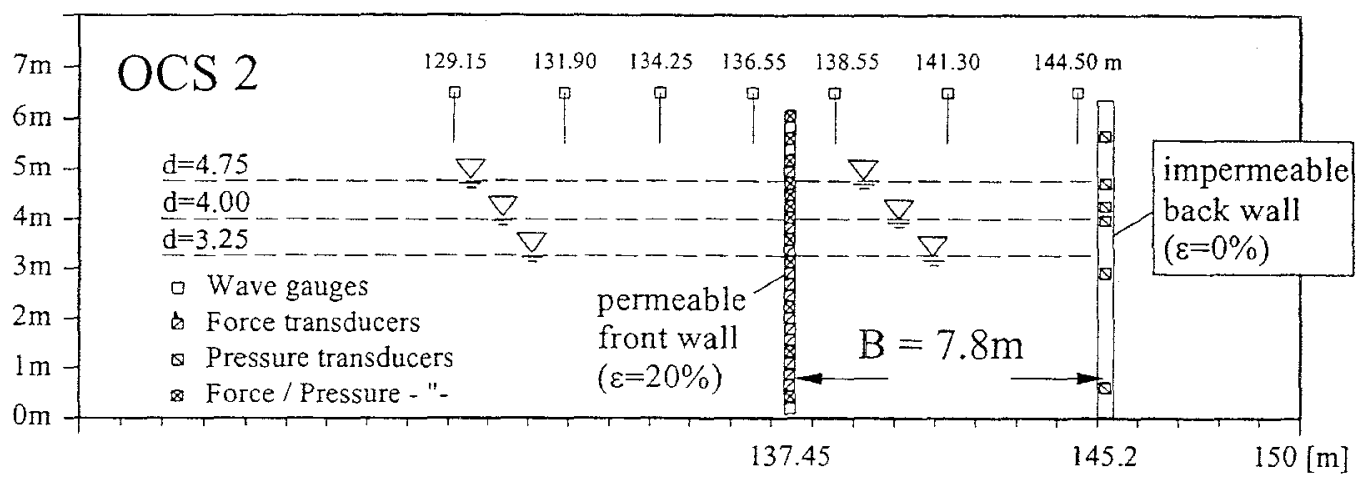

Fig. 1: Locations of measuring devices at One Chamber System OCS2. 
Additional wave gauges were installed to measure the water surface elevation at each perforated wall. The tests were carried out with regular waves $(H=0.5 \mathrm{~m}-1.5 \mathrm{~m}$ and $T=4.5-12 \mathrm{~s})$, wave spectra $\left(H_{s}=0.5-1.25 \mathrm{~m}, T_{p}=4.5-12 \mathrm{~s}\right)$, solitary waves and transient wave packets. The water depth was kept constant $(\mathrm{d}=4.0 \mathrm{~m})$ for OCS1 and MCS1 and varied between $\mathrm{d}=3.25 \mathrm{~m}, 4.00 \mathrm{~m}$ and $4.75 \mathrm{~m}$ for OCS2 and MCS2. The four different types of the investigated chamber systems are shown in Fig. 2.

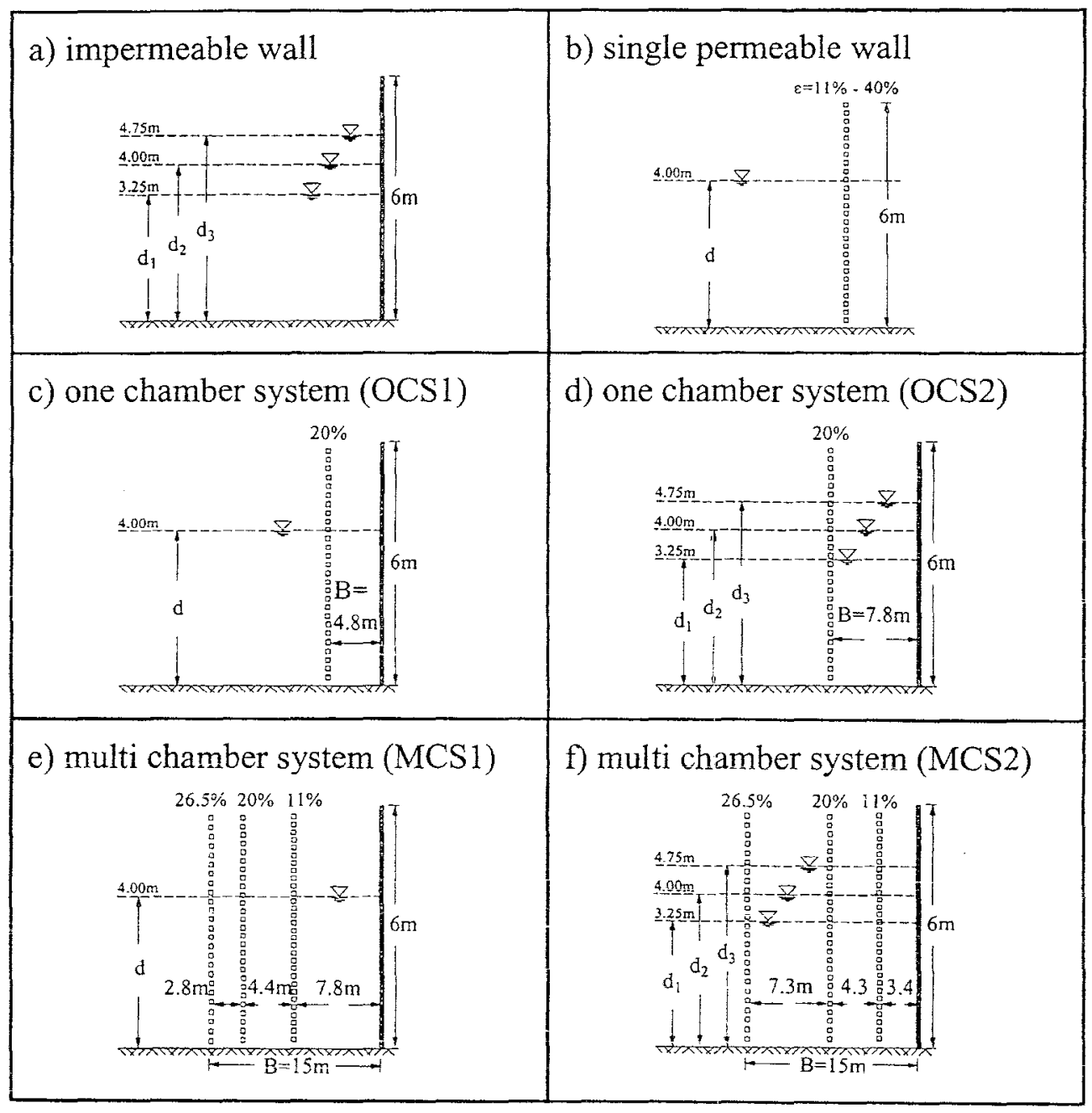

Fig. 2: Single walls and chambered structures investigated in the Large Wave Flume (GWK, Hannover).

\section{Discussion of results}

\subsection{Hydraulic Performance}

In cases where wave transmission has to be completely avoided (e.g. to achieve sufficient operating time of sea ports) single permeable walls do not provide sufficient protection, hence structures with an impermeable wall have to be considered. 
The one chamber system, similar to the Jarlan type caisson breakwater, can be very efficient in terms of energy dissipation due to the influence of the wave chamber and the perforated front wall. The incident wave energy is partly reflected at the perforated seaward wall and partly transmitted through the openings into the breakwater chamber. In the wave chamber a certain amount of the energy is dissipated due to resonance phenomena and flow separation governed mainly by the porosity of the perforated wall and by the $B / L$ ratio. The smaller waves are subjected to relatively low energy dissipation and negligible reflection at the perforated wall. Hence, in contrast to single filters, with OCS smaller wave heights lead to higher reflection, due to total reflection of the transmitted wave energy at the impermeable back wall (Bergmann \& Oumeraci, 1999). In One Chamber Systems (porosity of frontwall $\varepsilon=20 \%$ ) the impermeable back wall contributes to the main part of the reflected wave energy. This effect results in strong waterlevel fluctuations in the wave chamber which are influencing the hydraulic conditions at the perforated wall. Fig. 3 illustrates the wave damping efficiency of OCS and MCS over a certain range of relative chamber width for wave spectra. The limited effiency of the OCS (conventional Jarlan Caisson) for a certain range in the frequency band is apparent. The maximum energy dissipation occurs at $\mathrm{B} / \mathrm{L}=0.2$. The impermeable vertical wall (without chamber $\mathrm{B} / \mathrm{L}=0$ ) provides a reflection coefficient $\mathrm{Cr}=0.92-0.97$.

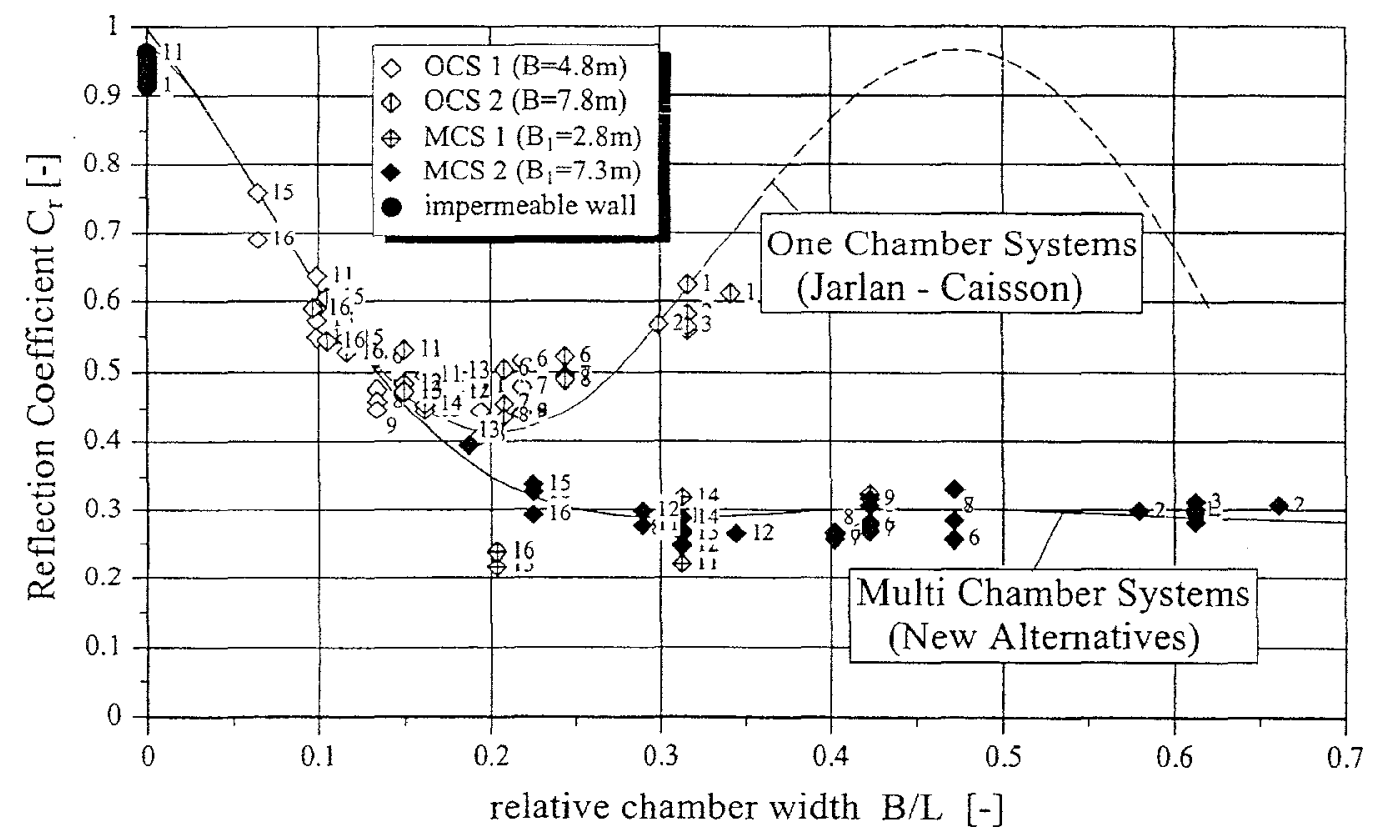

Fig. 3: Relation between reflection coefficient and relative chamber width. Comparison of OCS and MCS (wave spectra, GWK).

In comparison to the conventional Jarlan Caisson breakwater (OCS), MultiChamber-Systems are less selective with respect to the frequency of the incident waves and provide lower wave reflection, if the overall length of the chamber system is larger than approximately $0.3 \cdot \mathrm{L}$ (for MCS the overall length of the structu- 
re was taken as the chamber width $B$ ). Due to the multiple perforated walls the following benefits are achieved:

- $\quad$ reduced wave reflection even for large waves at the seaward wall due to higher porosity

- $\quad$ increased energy dissipation in the wave chambers

- $\quad$ phase lag of reflected waves between the four successive walls

- $\quad$ effective wave damping over a large $B / L$ range

\subsection{Wave loads}

Besides the advantages associated with the hydraulic performance a strong reduction of the resulting horizontal wave forces $\mathrm{F}_{\text {total }}^{+}$(maximum overall force, simultaneously measured at each wall) can be stated in comparison to the force of a single impermeable wall $\mathrm{F}_{0 \%}^{+}$(measured), especially for the MCS. Because of the strong interaction between surface elevation, wave reflection and wave forces, a very similar effect of the $B / L$ ratio is shown (Fig. 4). For MCS, shorter waves (B/L $>0.25$ ) would result in forces acting simultaneously in both seaward and shoreward directions at different walls of the system. As a result, a considerable reduction of the total force on the overall multichamber structure will be achieved. In contrast to maximum wave damping (at $B / L=0.2$, Fig. 3) the maximum force reduction occurs at approximately $\mathrm{B} / \mathrm{L}=0.25$.

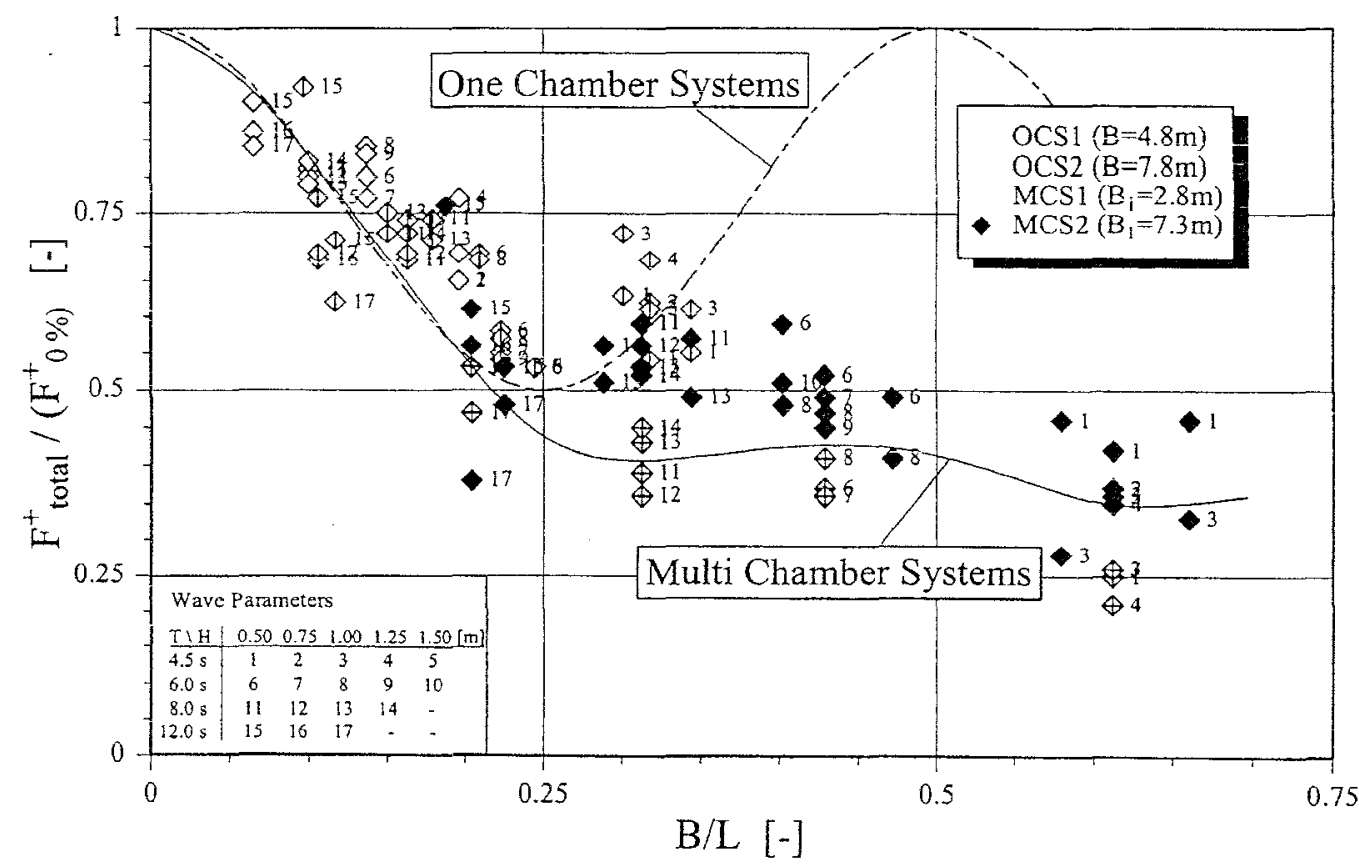

Fig. 4: Ratio of simultaneous overall force on OCS and MCS compared to a single permeable wall in relation to $B / L$ (regular waves, GWK). 


\subsection{Phase relations}

One of the further aspects of the hydraulic performance of OCS which should be highligted in this paper is concerned with the phase relations. As shown in Fig. 3 the optimal phase relation of the surface elevations at the front and rear wall has shifted from the theoretical value $\mathrm{B} / \mathrm{L}=0.25$ to a smaller $\mathrm{B} / \mathrm{L}$ ratio of 0.2 . This effect, which might be beneficial to reduce space and costs, is generated by a phase lag, occurring during the transmission through the permeable frontwall.

The theoretical phase difference $\varphi_{0}$ between the maximum surface elevation at the seaward wall and at the impermeable back wall is defined following linear wave theory

$$
\varphi_{0}=2 \pi \frac{\mathrm{B}}{\mathrm{L}}=\mathrm{k} \overline{\mathrm{B}}
$$

with $\mathrm{k}$ being the wave number. Fig. 5 shows, that longer waves follow the theoretical relation, but with decreasing wave length the actual phase difference $\varphi_{(1,3)}$ increases. This phase difference can be determined by using the following empirical equation:

$$
\varphi_{1,3}^{*}=3 \pi\left(\frac{\mathrm{B}}{\mathrm{L}}\right)^{1.15}
$$

This effect could be related to the relative water depth $d / L$ and might be induced by vertical energy transport due to the varying dynamic porosity of the front wall over the water depth. A direct relation to the $\mathrm{B} / \mathrm{L}$ ratio itself might also exist, which results from the stronger wave structure interactions and higher velocities at the

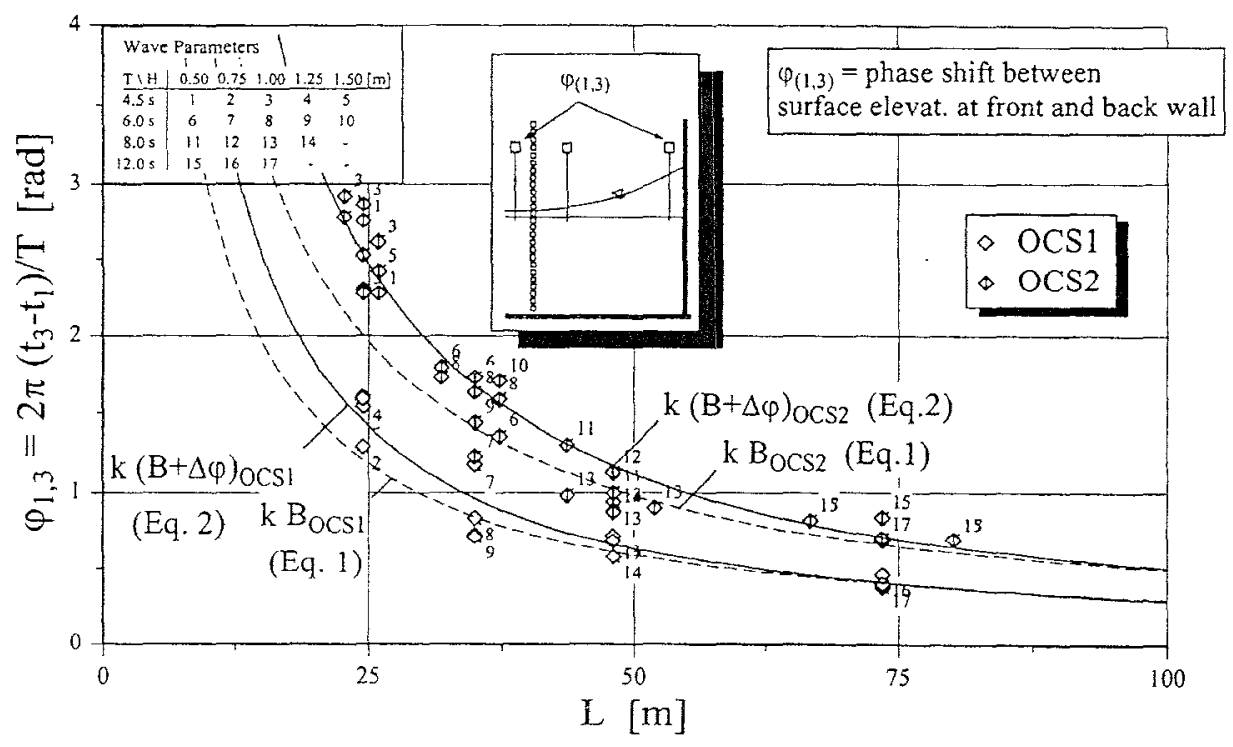

Fig. 5: Measured and theoretical phase difference of the OCS tested versus the wave length (regular waves, GWK). 
front wall for certain $\mathrm{B} / \mathrm{L}$ values near the theoretical optimum. Moreover, other parameters like the maximum difference of surface elevation in front and behind the seaward wall and the generation of higher harmonic components in the wave chamber may also contribute to this effect. With respect to this, further research would be needed to provide the required information on the effect of the front wall porosity and other structure properties (reduced chamber depths, berms, etc.) on the.hydraulic performance of these structures.

Given the phase relation of the wave forces acting on the front- and rear wall (Fig.6) it can be stated, that a phase shift also occurs, but at the optimum chamber width $(\mathrm{B} / \mathrm{L}$ around 0.25 ), theoretical and measured phase lags are of similar value (approx. $\left.\varphi_{(\mathrm{F} 1, \mathrm{FR})} / \varphi_{0}=1\right)$. The increase of the relative phase lag $\varphi_{(\mathrm{F} 1, \mathrm{FR})} / \varphi_{0}$ for longer waves is generated through the rapid rise of the water surface in the wave chamber at small $\mathrm{B} / \mathrm{L}$ ratios. This reduces the maximum force at the front wall and moves the time of its occurrence. The phase lag observed from surface elevations and from wave loads are not influenced by the same hydraulic processes. This has to be considered in the formulation of future theoretical approaches.

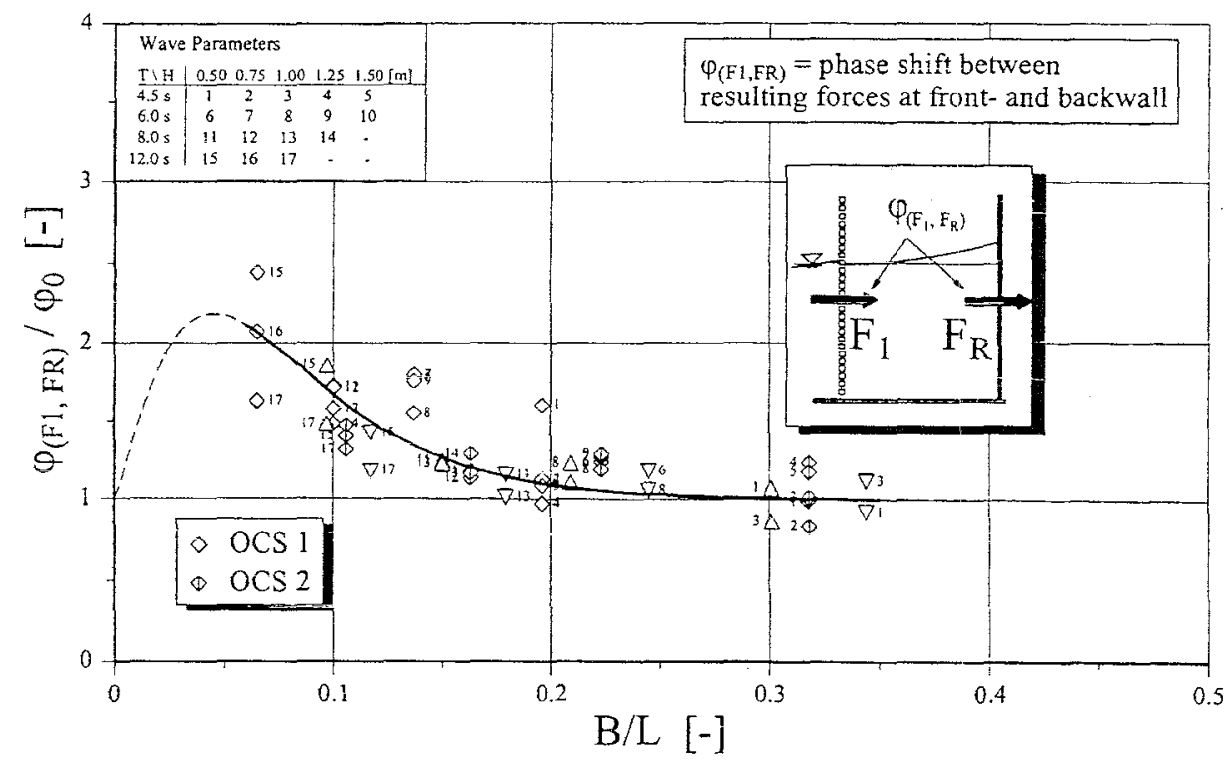

Fig. 6: Deviation from theoretical phase relation versus relative chamber width $\mathrm{B} / \mathrm{L}$.

\section{Concluding remarks and future work}

An innovative design to combine the advantages of vertical monolithic caisson breakwaters with the low refiectivity of rubble structures is given by the consideration of energy dissipating wave chambers with permeable front walls. The benefits of the new proposed permeable vertical structures are the following: 
- Applicable for large water depths and for limited space;

- Reduction of costs for construction material, transport, and construction time (Prefabrication of caisson units in dry docks and towing to final location);

- Good hydraulic performance in terms of wave reflection over a wide range of wave frequencies;

- Reduction of waterlevel oscillations in front of the structure (decreasing wave run-up, hence reduction of wave overtopping and spray);

- Safer navigation particularly for smaller vessels due to lower wave steepness in front of the breakwater/seawall;

- Reduction of scour risk at the structure toe;

- Enhancement of overall stability through the phase lag between wave loads on succeeding permeable walls (reduction of total load).

The recent investigations on One- and Multi-Chamber-Systems show the very high and stable efficiency of MCS in terms of energy dissipation. Detailed design rules for chamber systems have to be developed in the future. For effective wave damping, the relative chamber width should exceed a value $B / L=0.3$ (with $B=$ overall length of the dissipating chambers). The phase lag associated with water level elevations and wave loads is different due to the different processes involved. Considering the influence of a high berm in front of the structure, the overall structure width might be chosen smaller than for a flat bottom (on the other hand this might increase wave impacts). In this respect further research work is required to achieve an optimal design.

\section{Acknowledgements}

This study has been supported by the Federal Ministry of Education, Science, Research and Technology (BMBF), Bonn, Germany, within a joint project performed by the Technical Universities of Berlin and Braunschweig.

\section{References}

BERGMANN, H., OUMERACI, H. (1999) Hydraulic performance of perforated structures. Proceedings of Conference on Coastal and Port Engineering in Developing Countries (COPEDEC V), Cape Town, South Africa, pp. 1340-1349.

JARLAN, G.E. (1965) The application of acoustic theory to the reflective properties of coastal engineering structures. National Research Council Canada. DME/ NAE Quarterly Bulletin No. 1, Ottawa, pp. 23 - 63.

MANSARD, E.P.D., FUNKE, E.R. (1987) Experimental and analytical techniques in wave dynamics. Proceedings Congress of IAHR, Seminar on wave analysis and generation in laboratory basins, Lausanne, pp. $91-117$. 